\title{
Correction: LncRNA BCYRN1 inhibits glioma tumorigenesis by competitively binding with miR-619-5p to regulate CUEDC2 expression and the PTEN/AKT/p21 pathway
}

Maolin Mu, Wanxiang Niu, Xiaoming Zhang, Shanshan Hu (D) and Chaoshi Niu (D)

(c) The Author(s), under exclusive licence to Springer Nature Limited 2021

Oncogene (2021) 40:5972-5973; https://doi.org/10.1038/s41388-021-01990-4

Correction to: Oncogene

https://doi.org/10.1038/s41388-020-01466-x

Following publication of this article, it was noted that the incorrect image for PEGFP-C1-CUEDC2+miR-619-5p-mimic was presented in Fig. 5e. The correct figure, based on the original raw data, is shown below. This correction does not change the results or conclusions of this paper.

The original article has been corrected.

\begin{abstract}
(c) (i) Open Access This article is licensed under a Creative Commons adaptation, distribution and reproduction in any medium or format, as long as you give appropriate credit to the original author(s) and the source, provide a link to the Creative Commons license, and indicate if changes were made. The images or other third party material in this article are included in the article's Creative Commons license, unless indicated otherwise in a credit line to the material. If material is not included in the article's Creative Commons license and your intended use is not permitted by statutory regulation or exceeds the permitted use, you will need to obtain permission directly from the copyright holder. To view a copy of this license, visit http://creativecommons. org/licenses/by/4.0/.
\end{abstract}

(c) The Author(s), under exclusive licence to Springer Nature Limited 2021 
e

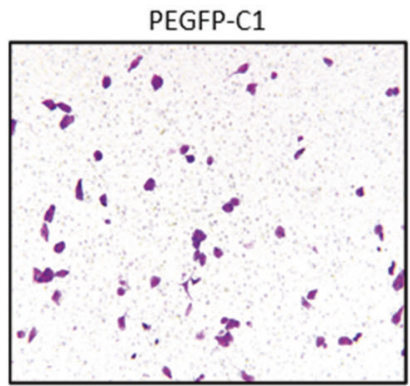

PEGFP-C1-CUEDC2

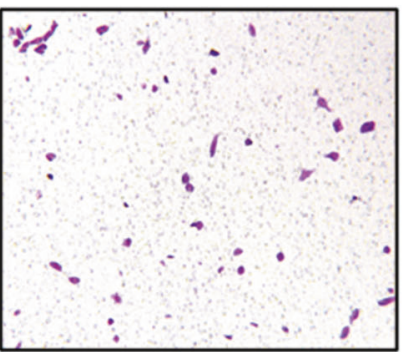

(U251)

Fig. $5 e$.

PEGFP-C1-CUEDC2+

miR-619-5p-mimic

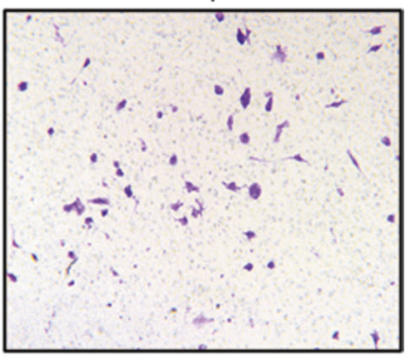

41 